\title{
Civil unrest, COVID-19 stressors, anxiety, and depression in the acute phase of the pandemic: a population-based study in Hong Kong
}

\author{
Wai Kai Hou ${ }^{1,2}$ (D) Tatia Mei-Chun Lee ${ }^{3}$ (D) Li Liang $^{2}$ (D) $\cdot$ Tsz Wai Li $^{2} \cdot$ Huinan Liu ${ }^{1,2} \cdot$ Catherine K. Ettman $^{4,5}$ (D) \\ Sandro Galea ${ }^{4}$ (D)
}

Received: 31 August 2020 / Accepted: 29 January 2021 / Published online: 16 February 2021

(c) Springer-Verlag GmbH, DE part of Springer Nature 2021

\begin{abstract}
Purpose To examine the joint associations of civil unrest and COVID-19 with probable anxiety and depression during the first half of 2020 in Hong Kong. Associations were compared between persons with low or high assets.

Methods A population-representative sample of 4011 Hong Kong Chinese residents aged 15 years or older were recruited between February and May 2020. Respondents reported current anxiety and depressive symptoms, unrest stress, COVID-19 stress, assets (savings and home ownership), and demographics.

Results Stress due to unrest and COVID-19 was associated with higher prevalence of probable anxiety and depression; persons with both stressors had higher prevalence. This pattern was consistent among persons with low or high assets, but the probabilities of mental disorder were substantially higher among persons with fewer assets.

Conclusions The effect of stressors on probable anxiety and depression are cumulative: persons with stress due to civil unrest and to COVID-19 reported more mental disorders than persons with stress due to only one, or none of these factors. Overall high assets appear to buffer the consequences of stressors, lowering the risk of mental disorder.
\end{abstract}

Keywords Anxiety · Depression · Civil unrest · COVID-19 · Assets

\section{Introduction}

Anti-extradition law amendment bill (anti-ELAB) movement was initiated following the introduction of a controversial bill that would have allowed people in Hong Kong to be extradited to Mainland China. Massive protests directed

Wai Kai Hou

wkhou@eduhk.hk

1 Department of Psychology, The Education University of Hong Kong, 10 Lo Ping Road, Tai Po NT,

Hong Kong SAR, China

2 Centre for Psychosocial Health, The Education University of Hong Kong, Hong Kong SAR, China

3 State Key Laboratory of Brain and Cognitive Sciences and Laboratory of Neuropsychology and Human Neuroscience, The University of Hong Kong, Hong Kong SAR, China

4 School of Public Health, Boston University, Boston, MA, USA

5 Department of Health Services, Policy, and Practice, Brown University School of Public Health, Providence, RI, USA towards the Hong Kong Special Administration Region (SAR) Government began in June 2019. Despite the Hong Kong government's eventual withdrawal of the bill, the antiELAB movement transformed into large-scale demonstrations and protests throughout Hong Kong. These protests escalated into violent clashes with police on the streets and in shopping malls, occupation of major roads and public transportation, and break-in and vandalism of government buildings and China-based shops, restaurants, and banks. The 2019-2020 anti-ELAB movement in Hong Kong is the largest scale social/political movement in terms of population participation in Greater China since the Umbrella Movement in 2014 and the Tiananmen Square protests in 1989. An estimated 1-2 million of the 7.5 million Hong Kong people reportedly participated in different forms of protests [1]. Over 9000 protesters have been arrested since June 2019, among whom 1972 have been prosecuted and 62 have been convicted at the time of writing.

Compounding this particular set of challenges, coronavirus disease 2019 (COVID-19) emerged in Hong Kong in late January 2020. COVID-19 eventually evolved into a pandemic affecting more than 200 countries or territories 
worldwide, almost 20 million confirmed cases and over 700,000 deaths to date. Different forms of lockdown, quarantine, and social distancing were implemented throughout Hong Kong, restricting the mobility of people within communities and countries and across countries and regions.

Significant mental disorder or emotional distress has been reported in populations during and after large-scale social movements [2, 3, 4], which can contribute to higher subsequent psychiatric symptoms [5]. In addition, emerging evidence is showing that the threat to health and the economic downturn of the COVID-19 pandemic likely also incur a burden on population mental health [6]. This suggests that Hong Kong residents were at particular risk of poor mental health during this period.

This study examined the joint associations of unrest stress and COVID-19 stress with probable anxiety and depression in the first half of 2020. Previous theoretic and empiric work suggests that the impact of stressors on mental health compounds [7]. In particular, existing evidence suggests that persons with fewer resources before large-scale events or with prior vulnerabilities-including persons with histories of childhood abuse [8] and younger adults with adolescent traumatic exposure [9]—would be at greater risk of poor mental health in this context. We, therefore, assessed the role that stressors related to the unrest and to COVID-19 played in shaping symptoms of probable anxiety and depression in Hong Kong, and the group that was most affected by these stressors. We were particularly interested in whether stressors and probable anxiety and depression differ across people with different levels of assets. Assets such as savings and cash or physical assets such as houses or apartments are related to lower risk of depression independent of socioeconomic resources including income and education level [10]. Assets could, therefore, be of particular relevance during crises in cities such as Hong Kong, where the costs of property rental are high and could lead to the deprivation of necessities, lower savings, and poorer mental health [11]. We anticipated that high unrest or high COVID-19 stress alone will be associated with higher odds of probable anxiety and depression, while combined high unrest stress and high COVID-19 stress (i.e., combined high stress) will demonstrate the strongest positive associations with odds of probable anxiety and depression. The positive associations of unrest stress and COVID-19 stress with probable mental disorders will be stronger among persons with low assets relative to those with high assets, controlling for the effects of sociodemographics.

\section{Methods}

\section{Respondents and procedure}

Upon obtaining Ethics Committee's approval from the university, the Centre for Communication and Public Opinion Survey and Hong Kong Public Opinion Research Institute were contracted to recruit respondents and conducted telephone interviews between February 25 and May 1, 2020. Random digit dialing was conducted using a ComputerAssisted Telephone Interview (CATI) system. A dual-frame approach of sampling with both landline and mobile phone numbers (50\% each) was utilized. Telephone numbers were randomly extracted from databases of telephone numbers released by the Hong Kong Communication Authority. Eligibility included (1) being a Hong Kong Chinese resident, (2) 15 years of age or older, and (3) Cantonese-speaking. For the landline phone calls, if multiple household members were eligible after successful contact, the one with the closest birthday to the interview date was selected. CATI arranged further attempts for numbers that were "no answer," "busy," or "eligible respondent not at home." Oral informed consent was obtained at the beginning of the interview. All interviews were conducted during both working and non-working hours from 2 to $10 \mathrm{pm}$ on weekdays and weekends. A total of 4011 respondents were recruited (response rate $=38.3 \%$, cooperation rate $=70.3 \%$, error $= \pm 2.7 \%(95 \% \mathrm{CI}))$. The participation and nonparticipation rates were acceptable and comparable with population-representative samples in prior studies in Hong Kong [2, 12, 13]. Detailed sampling information is summarized in Online Resource 1.

\section{Measurements}

Unrest stress. Respondents reported to what extent they felt distressed in the past 3 months by (1) government's handling of unrest, (2) confrontation between the police and the protestors, and the use of riot control measures including physical assault, tear gas, and rubber bullets, and (3) widespread and continuous demonstrations and protests. Respondents rated the three items on a 4-point scale $(0=$ not at all, $1=$ some, $2=$ quite a bit, $3=\mathrm{alot}$ ). Scores of each item were recoded into low (not at all/some) and high (quite a bit/a lot). Items are summarized in Online Resource 2.

COVID-19 stress. Respondents reported the extent to which they worried about being infected with COVID-19 or rated three items on perceived threat of life, long-term ill health, and treatment side-effect if they were infected with COVID-19 on a 4-point scale (Online Resource 2). Scores of the worry item were recoded into low (not at all/a little) and high (some/very much). The summed scores for health/ 
life threat (Cronbach's alpha $=0.81)$ were recoded into low and high by median split.

Probable anxiety. The Chinese version of the 7-item Generalized Anxiety Disorder (GAD-7) was used to assess anxiety symptoms in the past 2 weeks [14]. Severity of each symptom was rated on a 4 -point scale $(0=$ not at all, $1=$ on several days, $2=$ on more than half of the days, $3=$ nearly every day). Summed scores ranged from 0 to 21 . Higher scores indicated greater severity of anxiety symptoms. The measure showed high internal consistency (Cronbach's $\alpha=0.92$ ) and negative correlations with different dimensions of self-rated health status across different populations [14]. Scores of 10 or higher were used to indicate clinical levels of anxiety symptoms [15]. Cronbach's alpha in this study was 0.93 .

Probable depression. The Chinese version of the 9-item Patient Health Questionnaire (PHQ-9) [16] was used to assess depressive symptoms in the previous two weeks on the same 4-point scale as GAD-7. Higher scores indicated higher depressive symptoms (range $=0-27$ ). The Chinese version has demonstrated high internal consistency among Chinese $(\alpha>0.80)$ [16]. Based on the previous populationbased studies among Chinese and results of an individual participant data meta-analysis [17], scores at or exceeding 10 were used to define depression. In this study, Cronbach's alpha was 0.86 .

Assets. Savings indicated a liquid asset whereas home ownership indicated a physical asset [10, 18]. Respondents reported their savings in seven categories: none, less than HK\$200,000; HK\$200,000-\$499,999; HK\$500,000-\$999,999; HK\$1,000,000-\$1,999,999; HK $\$ 2,000,000-\$ 2,999,999$; and HK\$3,000,000 or above (US\$1 $\approx$ HK\$7.80). They were reminded to take into account cash, money in savings or checking accounts, stocks, bonds, mutual/insurance funds, and retirement funds (i.e., Mandatory Providence Fund or pensions). Savings were recoded into low $(<\mathrm{HK} \$ 200,000)$ and high $(\geq \mathrm{HK} \$ 200,000)$ according to Hong Kong population census data [19]. Respondents also reported whether or not they owned any houses/apartments on a binary scale (no/yes). Low assets were defined as low savings and no home ownership, whereas high assets referred to high savings and/or home ownership.

Demographics. We used a standardized proforma to ask respondents' age in years, gender (female vs. male), marital status (unmarried/divorced/widowed vs. married/ cohabitating), education level (primary or below and secondary vs. tertiary or above), employment status (dependent/unemployed vs. employed), monthly household income $(\leq \mathrm{HK} \$ 19,999$, HK $\$ 20,000-\$ 39,999$, HK\$40,000-\$59,999, and HK\$60,000-\$79,999 vs. $\geq$ HK\$80,000), and income change since the COVID-19 outbreak (decreased vs. increased/stable).

\section{Analytic plan}

Multiple imputation replaced missing data $(<1 \%)$. Unrest stress referred to high scores (quite a bit/a lot) on perceived stress from at least one of the three dimensions: government's handling, police's confrontation with protests and riot control, and widespread protests. COVID-19 stress referred to high scores on worry (quite a bit/a lot) or high health/ life threat (>median). Four stress groups were created: (1) low unrest stress and low COVID-19 stress, (2) high unrest stress and low COVID-19 stress, (3) low unrest stress and high COVID-19 stress, and (4) high unrest stress and high COVID-19 stress. Prevalences of probable anxiety and depression in each stress group were illustrated for persons with low and high assets separately.

The group variable, together with gender, age group, marital status, education level, employment status, monthly household income, and income change, were included in adjusted multivariable logistic regression models. We included socioeconomic status (SES) and demographic variables that have been found to be closely associated with poorer mental health during ordinary time [20] or major crises including the current COVID-19 pandemic [2, 21]. Additional analysis tested the interaction effects between unrest stress and COVID-19 stress on probable anxiety and depression. Analyses were performed among respondents with low and high assets, respectively. In addition, giving the direct role of assets in protecting against mental health problems during the current COVID-19 pandemic [22], we also tested the interaction effects between stress group and assets on probable anxiety and depression to compare the stress group-outcome associations between low and high assets. Adjusted odds ratio (aOR) with 95\% confidence interval $(\mathrm{CI})$ indicated the associations of demographic and socioeconomic variables and the stress variables with each outcome. The logistic regression was conducted using the glm function of Stats Package in R software environment.

\section{Results}

\section{Descriptive results}

The current sample resembled the population in terms of gender, age group distribution, and education level [23]. Sociodemographic characteristics of the sample are summarized in Table 1. Figures 1 and 2 show the prevalences of probable anxiety and depression. Highest prevalences were observed among respondents reporting combined high stress (low assets: $31.5-33.9 \%$; high assets: $21.8-22.8 \%$ ) and lowest among respondents reporting low stress overall (low assets: $3.5-14.6 \%$; high assets: 3.8-6.1\%). Prevalences were similar between respondents reporting low 
Table 1 Sociodemographic characteristics of the sample ( $n=4011$

\begin{tabular}{|c|c|c|}
\hline & \multicolumn{2}{|c|}{ Overall $(n=4011)$} \\
\hline & $n$ & $\%$ \\
\hline \multicolumn{3}{|l|}{ Gender } \\
\hline Male & 1816 & 45.3 \\
\hline Female & 2195 & 54.7 \\
\hline \multicolumn{3}{|l|}{ Age } \\
\hline $15-24$ & 579 & 14.4 \\
\hline $25-34$ & 769 & 19.2 \\
\hline $35-44$ & 769 & 19.2 \\
\hline $45-64$ & 1315 & 32.8 \\
\hline 65 or above & 579 & 14.4 \\
\hline \multicolumn{3}{|l|}{ Marital status } \\
\hline Married & 2221 & 55.4 \\
\hline Unmarried/divorced/widowed & 1790 & 44.6 \\
\hline \multicolumn{3}{|l|}{ Education level } \\
\hline Tertiary or above & 2019 & 50.3 \\
\hline Secondary & 1703 & 42.5 \\
\hline Primary or no formal education & 289 & 7.2 \\
\hline \multicolumn{3}{|l|}{ Employment status } \\
\hline Employed & 2458 & 61.3 \\
\hline Dependent & 1390 & 34.7 \\
\hline Unemployed & 163 & 4.1 \\
\hline \multicolumn{3}{|l|}{ Monthly household income $(\mathrm{HK} \$)^{\mathrm{a}}$} \\
\hline$\$ 80,000$ or above & 636 & 15.9 \\
\hline$\$ 60,000-\$ 79,999$ & 356 & 8.9 \\
\hline$\$ 40,000-\$ 59,999$ & 869 & 21.7 \\
\hline$\$ 20,000-\$ 39,999$ & 1177 & 29.3 \\
\hline$\$ 19,999$ or below & 973 & 24.3 \\
\hline \multicolumn{3}{|l|}{ Income change } \\
\hline Increased/stable & 2699 & 67.3 \\
\hline Decreased & 1312 & 32.7 \\
\hline
\end{tabular}

${ }^{\mathrm{a} U S} \$ 1 \approx \mathrm{HK} \$ 7.80$

unrest stress and high COVID-19 stress and those reporting high unrest stress and low COVID-19 stress (low assets: differences $=0-2.1 \%$; high assets: differences $=0.5-1.2 \%$ ). Higher odds of probable anxiety and depression were found in respondents with low assets relative to those with high assets (differences $=8.5-12.1 \%$ ), except for probable anxiety in the absence of both unrest and COVID-19 stress. The statistics are summarized in Table 2.

\section{Logistic regression models}

Low assets. Controlling for demographic and socioeconomic variables, higher odds of probable anxiety were found among respondents reporting high unrest stress and low COVID-19 stress ( $\mathrm{aOR}=5.4,95 \% \mathrm{CI}=2.7-11.1)$, low unrest stress and high COVID-19 stress (aOR $=4.6,95 \%$ $\mathrm{CI}=2.0-10.4)$, and combined high stress $(\mathrm{aOR}=13.1$,
95\% CI $=6.6-26.1$ ), relative to those with overall low stress. Higher odds of probable depression were found among respondents reporting high unrest stress and low COVID-19 stress $(\mathrm{aOR}=1.6,95 \% \mathrm{CI}=1.1-2.5)$ and combined high stress $(\mathrm{aOR}=3.4,95 \% \mathrm{CI}=2.3-5.0)$. The results are summarized in Table 3 . The interaction effects between unrest stress and COVID-19 stress were nonsignificant on probable anxiety and depression (Online Resource 3).

High assets. Controlling for demographic and socioeconomic variables, higher odds of probable anxiety were found among respondents reporting combined high stress $(\mathrm{aOR}=5.8,95 \% \mathrm{CI}=3.2-10.3)$, relative to those with overall low stress. Higher odds of probable depression were found among respondents reporting high unrest stress only ( $\mathrm{aOR}=1.8,95 \% \mathrm{CI}=1.1-3.0)$ and combined high stress (aOR $=4.6,95 \% \mathrm{CI}=2.8-7.4)$. The results are summarized in Table 3. The interaction effect between unrest stress and COVID-19 stress was significant on probable anxiety $(p=0.04)$ but non-significant on probable depression $(p=0.16)$ (Online Resource 3). The positive associations of unrest stress and COVID-19 stress with probable anxiety was significant only in the presence of the other $(\mathrm{aOR}=5.8$, 95\% CI $=3.2-10.3, p<0.01)$.

Interactions between stress group and assets. Significant interaction effects between stress group and assets were found on probable anxiety $(p s<0.05)$ but not on probable depression ( $p s>0.05$ ) (Online Resource 4). Specifically, the positive association of low unrest stress and high COVID19 stress with probable anxiety was significant at low assets $(\mathrm{aOR}=3.2,95 \% \mathrm{CI}=1.5-6.7)$ but not at high assets $(\mathrm{aOR}=1.2,95 \% \mathrm{CI}=0.5-3.3)$. The positive association of high unrest stress and low COVID-19 stress with probable anxiety was significant at low assets $(\mathrm{aOR}=3.5,95 \%$ $\mathrm{CI}=1.9-6.6)$ but non-significant at high assets $(\mathrm{aOR}=1.6$, 95\% CI $=0.9-3.1$ ). Relative to those with overall low unrestCOVID-19 stress, respondents reporting combined high stress showed higher odds of probable anxiety whether they reported low assets $(\mathrm{aOR}=8.5,95 \% \mathrm{CI}=4.7-15.2)$ or high assets $(\mathrm{aOR}=6.3,95 \% \mathrm{CI}=3.5-11.2)$ (Online Resource 5).

\section{Discussion}

The present study investigated the joint associations of unrest stress and COVID-19 stress with the odds of probable anxiety and depression in a population-representative sample of Hong Kong Chinese. We found higher prevalences of probable anxiety and depression among respondents reporting combined high stress overall. The risks of probable anxiety and depression were higher among respondents with low assets (i.e., low savings and no home ownership), relative to those with high assets (i.e., high savings and/or home 
Fig. 1 Prevalence (\%) of probable anxiety across different stressors among respondents with low and high assets
Probable anxiety
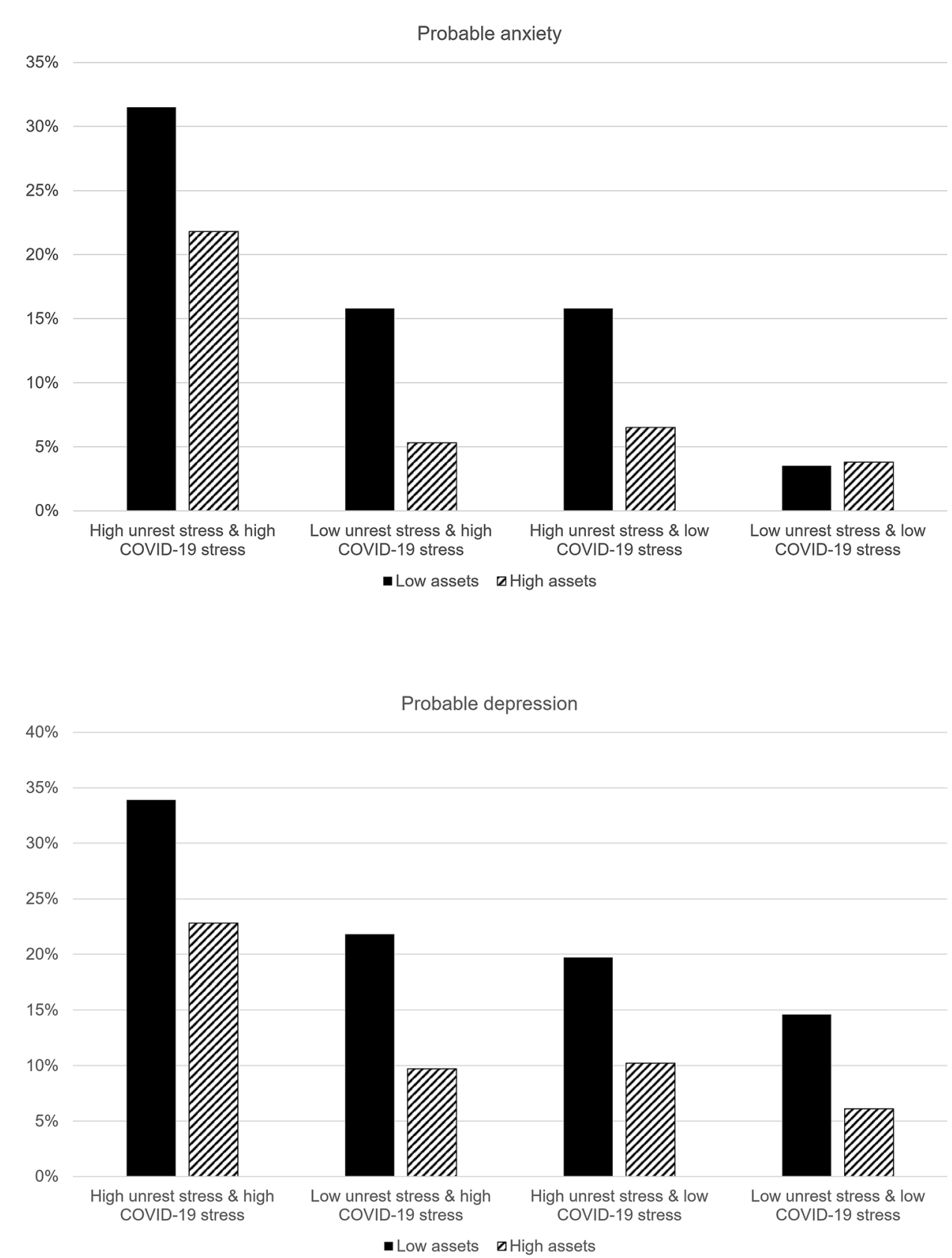

Low assets $\square$ High assets
Fig. 2 Prevalence (\%) of probable depression across different stressors among respondents with low and high assets

Table 2 Prevalence of probable anxiety and depression in each stress group by low and high assets

\begin{tabular}{|c|c|c|c|c|c|c|}
\hline & \multicolumn{3}{|c|}{ Low assets $(n=1779)$} & \multicolumn{3}{|c|}{ High assets $(n=2232)$} \\
\hline & $\begin{array}{l}\text { Number of } \\
\text { respondents }\end{array}$ & $\begin{array}{l}\text { Anxiety }^{\mathrm{a}} \\
\%(n)\end{array}$ & $\begin{array}{l}\text { Depression }^{\mathrm{b}} \\
\%(n)\end{array}$ & $\begin{array}{l}\text { Number of } \\
\text { respondents }\end{array}$ & $\begin{array}{l}\text { Anxiety }^{\mathrm{a}} \\
\%(n)\end{array}$ & $\begin{array}{l}\text { Depression }^{\mathrm{b}} \\
\%(n)\end{array}$ \\
\hline Low unrest stress, low COVID-19 stress & 254 & $3.5(9)$ & $14.6(37)$ & 342 & $3.8(13)$ & $6.1(21)$ \\
\hline High unrest stress, low COVID-19 stress & 507 & $15.8(80)$ & $19.7(100)$ & 782 & $6.5(51)$ & $10.2(80)$ \\
\hline Low unrest stress, high COVID-19 stress & 133 & $15.8(21)$ & $21.8(29)$ & 113 & $5.3(6)$ & $9.7(11)$ \\
\hline High unrest stress, high COVID-19 stress & 885 & $31.5(279)$ & $33.9(300)$ & 995 & $21.8(217)$ & $22.8(227)$ \\
\hline
\end{tabular}

${ }^{\mathrm{a}} \mathrm{GAD}-7$ scores $\geq 10$ were used to define probable anxiety

${ }^{\mathrm{b}} \mathrm{PHQ}-9$ scores $\geq 10$ were used to define probable depression 
Table 3 Multivariable logistic regression examining the associations of unrest stress and COVID-19 stress with probable anxiety and depression by low and high assets

\begin{tabular}{|c|c|c|c|c|c|c|c|c|}
\hline & \multicolumn{4}{|c|}{ Low assets $(n=1779)$} & \multicolumn{4}{|c|}{ High assets $(n=2232)$} \\
\hline & \multicolumn{2}{|l|}{ Anxiety $^{a}$} & \multicolumn{2}{|l|}{ Depression $^{\mathrm{b}}$} & \multicolumn{2}{|l|}{ Anxiety $^{a}$} & \multicolumn{2}{|l|}{ Depression $^{\mathrm{b}}$} \\
\hline & $\mathrm{aOR}(95 \% \mathrm{CI})$ & $P$ & $\mathrm{aOR}(95 \% \mathrm{CI})$ & $P$ & $\mathrm{aOR}(95 \% \mathrm{CI})$ & $P$ & $\mathrm{aOR}(95 \% \mathrm{CI})$ & $P$ \\
\hline \multicolumn{9}{|l|}{ Gender } \\
\hline Male & 1.0 & & 1.0 & & 1.0 & & 1.0 & \\
\hline Female & $1.2(0.9-1.6)$ & 0.14 & $1.2(1.0-1.6)$ & 0.07 & $1.4(1.1-1.8)$ & 0.02 & $1.3(1-1.7)$ & 0.03 \\
\hline \multicolumn{9}{|l|}{ Age } \\
\hline $15-24$ & 1.0 & & 1.0 & & 1.0 & & 1.0 & \\
\hline $25-34$ & $1.5(1.0-2.3)$ & 0.03 & $1.4(0.9-2.0)$ & 0.10 & $0.9(0.4-1.8)$ & 0.73 & $0.8(0.4-1.7)$ & 0.65 \\
\hline $35-44$ & $1.4(0.8-2.2)$ & 0.21 & $1.5(0.9-2.3)$ & 0.09 & $0.8(0.4-1.7)$ & 0.61 & $1.0(0.5-2.0)$ & 0.99 \\
\hline $45-64$ & $1.1(0.7-1.8)$ & 0.57 & $1.2(0.8-1.8)$ & 0.32 & $0.4(0.2-0.9)$ & 0.02 & $0.7(0.4-1.5)$ & 0.42 \\
\hline 65 or above & $0.9(0.5-1.5)$ & 0.61 & $1.4(0.9-2.3)$ & 0.14 & $0.5(0.2-1.1)$ & 0.07 & $0.7(0.3-1.5)$ & 0.37 \\
\hline \multicolumn{9}{|l|}{ Marital status } \\
\hline Married & 1.0 & & 1.0 & & 1.0 & & 1.0 & \\
\hline $\begin{array}{l}\text { Unmarried/divorced/wid- } \\
\text { owed }\end{array}$ & $1.4(1.1-1.9)$ & 0.02 & $1.5(1.1-1.9)$ & 0.01 & $1.1(0.8-1.4)$ & 0.72 & $1.3(1.0-1.7)$ & 0.06 \\
\hline \multicolumn{9}{|l|}{ Education level } \\
\hline Tertiary or above & 1.0 & & 1.0 & & 1.0 & & 1.0 & \\
\hline Secondary & $1.4(1.0-1.8)$ & 0.03 & $1.4(1.1-1.8)$ & 0.01 & $0.9(0.6-1.2)$ & 0.44 & $1.4(1.0-1.8)$ & 0.03 \\
\hline $\begin{array}{l}\text { Primary or no formal } \\
\text { education }\end{array}$ & $1.8(1.1-3.2)$ & 0.03 & $1.6(1.0-2.6)$ & 0.06 & $0.9(0.4-1.9)$ & 0.79 & $2.2(1.3-3.9)$ & 0.01 \\
\hline \multicolumn{9}{|l|}{ Employment status } \\
\hline Employed & 1.0 & & 1.0 & & 1.0 & & 1.0 & \\
\hline Dependent & $1.2(0.9-1.7)$ & 0.19 & $1.1(0.8-1.5)$ & 0.53 & $1.3(0.9-1.9)$ & 0.18 & $1.3(0.9-1.8)$ & 0.19 \\
\hline Unemployed & $2.3(1.4-3.6)$ & $<0.01$ & $2.3(1.5-3.6)$ & $<0.01$ & $1.2(0.5-2.7)$ & 0.71 & $1.1(0.5-2.3)$ & 0.84 \\
\hline \multicolumn{9}{|c|}{ Monthly household income $(\mathrm{HK} \$)^{\mathrm{c}}$} \\
\hline$\$ 80,000$ or above & 1.0 & & 1.0 & & 1.0 & & 1.0 & \\
\hline$\$ 60,000-\$ 79,999$ & $0.9(0.5-2.0)$ & 0.88 & $0.7(0.3-1.4)$ & 0.28 & $1.1(0.7-1.8)$ & 0.56 & $1.3(0.8-2.0)$ & 0.35 \\
\hline$\$ 40,000-\$ 59,999$ & $1.4(0.8-2.4)$ & 0.30 & $1.2(0.7-2.0)$ & 0.56 & $1.5(1.1-2.2)$ & 0.02 & $1.8(1.2-2.6)$ & $<0.01$ \\
\hline$\$ 20,000-\$ 39,999$ & $1.3(0.7-2.2)$ & 0.40 & $1.3(0.8-2.2)$ & 0.24 & $1.1(0.7-1.7)$ & 0.61 & $1.6(1.1-2.4)$ & 0.01 \\
\hline$\$ 19,999$ or below & $1.3(0.7-2.3)$ & 0.35 & $1.2(0.7-2.0)$ & 0.48 & $1.2(0.7-2.0)$ & 0.54 & $1.7(1.1-2.7)$ & 0.02 \\
\hline \multicolumn{9}{|l|}{ Income change } \\
\hline Increased/stable & 1.0 & & 1.0 & & 1.0 & & 1.0 & \\
\hline Decreased & $1.4(1.1-1.8)$ & $<0.01$ & $1.3(1.0-1.6)$ & 0.03 & $1.4(1.1-1.9)$ & 0.01 & $1.3(1.0-1.6)$ & 0.08 \\
\hline \multicolumn{9}{|l|}{ Stress group } \\
\hline $\begin{array}{l}\text { Low unrest stress and low } \\
\text { COVID-19 stress }\end{array}$ & 1.0 & & 1.0 & & 1.0 & & 1.0 & \\
\hline $\begin{array}{l}\text { High unrest stress and low } \\
\text { COVID-19 stress }\end{array}$ & $5.4(2.7-11.1)$ & $<0.01$ & $1.6(1.1-2.5)$ & 0.02 & $1.6(0.8-2.9)$ & 0.17 & $1.8(1.1-3.0)$ & 0.02 \\
\hline $\begin{array}{l}\text { Low unrest stress and high } \\
\text { COVID-19 stress }\end{array}$ & $4.6(2.0-10.4)$ & $<0.01$ & $1.5(0.9-2.6)$ & 0.14 & $1.2(0.5-3.3)$ & 0.68 & $1.4(0.7-3.1)$ & 0.38 \\
\hline $\begin{array}{l}\text { High unrest stress and high } \\
\text { COVID-19 stress }\end{array}$ & $13.1(6.6-26.1)$ & $<0.01$ & $3.4(2.3-5.0)$ & $<0.01$ & $5.8(3.2-10.3)$ & $<0.01$ & $4.6(2.8-7.4)$ & $<0.01$ \\
\hline
\end{tabular}

$O R$ adjusted odds ratio, $C I$ confidence interval

${ }^{\mathrm{a}} \mathrm{GAD}-7$ scores $\geq 10$ were used to define probable anxiety

${ }^{\mathrm{b}} \mathrm{PHQ}-9$ scores $\geq 10$ were used to define probable depression

${ }^{\mathrm{c}} \mathrm{US} \$ 1 \approx \mathrm{HK} \$ 7.80$ 
ownership). Among persons with low assets, high unrest stress and high COVID-19 stress, whether individually or combined, were associated with higher odds of probable anxiety, whereas at high assets only combined high stress was associated with a greater risk of probable anxiety. High unrest stress and combined high stress were positively associated with the odds of probable depression across low and high assets.

We found that stress due to social unrest was an important determinant of anxiety and depressive symptoms even in the context of COVID-19 infection threat and the significant impact of infection control measures on people's life [24, 25]. While this is consistent with past work on the relationship between civil unrest and poor mental health around the world including Hong Kong [3, 26], the observation of an increase in mental disorders despite ongoing threats from the pandemic is a sobering reflection on the importance of civil unrest and conflict for population mental health, and a concern that is ever more salient as civil unrest rises worldwide [27].

Our findings of increased mental disorders linked to stress due to COVID-19 is consistent with prior studies that have demonstrated a mental health toll of large-scale severe infectious diseases, including severe acute respiratory syndrome (SARS) [12], Ebola [28], and Middle East Respiratory Syndrome (MERS) [29]. Anxiety symptoms have been found to change during and after the outbreak of the SARS among population-representative samples, with levels peaking at the beginning of the SARS outbreak and then declining to baseline level post-epidemic [12]. There is evidence that the incidence of psychiatric disorders including anxiety and depression remained high at 12 months post-MERS among survivors in South Korea [30] and 30 months post-SARS among Chinese survivors in Hong Kong [31].

We found clear evidence of the cumulative effect of stressors in shaping mental disorders. This is consistent with sensitization [32] and stress proliferation [7] hypotheses whereby the effect of stressors compounds the effect of other stressors, contributing to worse population mental health. While there is relatively little literature that has shown the effect of cumulative stressors, most available evidence primarily focuses on how distal traumatic exposure such as childhood abuse relates to stressors in adulthood and, in turn, contributes to poorer mental health $[8,9]$. Processes of stress proliferation have been investigated among persons with significant chronic stressors such as AIDS caregiving [7] and parenting for children with autism spectrum disorder [33].

Hong Kong is known as one of the world's wealthiest societies, paradoxically with serious income inequality in comparison with other leading economies. Hong Kong is among the most unequal cities across the globe with a Gini coefficient of 0.539 [34]. Poverty and poor mental health are positively interrelated, and specifically, low SES could be a risk factor for mental health problems [35]. The definition of SES is broad whereas the measurement of SES is equivocal across prior studies [34-38]. Previous evidence showed that lower income, poorer employment status such as lower grade/rank of employment, and lower education level are common SES indicators that predicted poorer mental health outcomes [20, 35, 39]. Recent studies have extended the understanding of the positive links between poverty and mental health problems beyond these common SES indicators. A deprivation index (DI) has been used to indicate objective material and social deprivations independent of monetary income poverty. Deprivation was associated with higher levels of perceived stress and anxiety symptoms independent of sociodemographics [54].

In addition to deprivation, there is evidence showing a positive association between assets (e.g., properties and savings) and mental health independent of sociodemographics [10]. Assets can be understood as a long-term SES that is accumulated over time and remains relatively stable in the short run at the time of income change [40]. Consecutive large-scale crises like social unrest and COVID-19 have had adverse impact on Hong Kong economy. Massive civil unrest interfered with local commerce and transportation in the latter half of 2019 [41], whereas COVID-19 has posed major challenges to economic activities globally since early 2020 [42]. Many industries such as tourism, retails, and aviation have been experiencing a significant plummet in business, resulting in mass layoffs [42]. Many people experienced reduced salaries, were placed on furlough, or even lost their jobs. In one of the most expensive cities with high costs of living especially on consumer goods and housing [43], there are neither specialized insurance nor assistance systems for unemployed persons in Hong Kong [44]. Hong Kong people could face more challenges in maintaining their standard of living during such a hard time than their counterparts in other more developed cities in the UK or the US. Access to liquid and physical assets such as savings and properties could have a strong buffering effect on the negative mental health impact of unrest and COVID-19 stressors beyond SES among Hong Kong citizens [22].

Assets, particularly savings and home ownership, could be an important determinant of the association between compound stressors and probable anxiety and depression during a period of heightened stress due to social unrest and a pandemic. This reflects the centrality of assets as a protective factor for population mental health. While there is substantial evidence about the role of socioeconomic status, typically defined as income [45], as a determinant of mental health, there is substantially less evidence about the role of assets more generally. However, there is a growing body of literature showing that having assets outside of income protects against mental illnesses from depressive symptoms 
[10] to suicidal ideation [46]. The adverse role of low assets in the context of mental health during times of crises is noteworthy and often overlooked, even if it is not necessarily surprising. Assets including savings and household possessions have been associated with lower psychological distress and depressive symptoms independent of income in countries without crises $[47,48]$. Low-wage workers in manual labor and unskilled jobs are exposed both to a higher risk of infection and poor mental health at a time when populations are facing significant increases in unemployment triggered by COVID-19 infection control [42]. Persons with fewer assets, to begin with, facing a higher likelihood of unemployment amid the pandemic, are then plausibly at greater risk of poor mental health [10, 27, 49].

Disruption to daily routines is associated with poorer mental health during crises [26, 55]. It is possible that having assets such as liquid savings can help to avoid or minimize disruptions due to social unrest; for example, persons with high assets may be more likely to use private transportation and have fewer disruptions from social unrest than persons with low assets, who may rely on public transportation and other services that were disrupted during the Hong Kong protests. Similarly, persons with high assets may be better able to protect themselves from COVID-19, by avoiding crowded public places, by being able to work remotely, and by residing in more spacious housing that allows for social distancing, minimizing contagion. Meanwhile, persons with low assets may be affected more by the social unrest and may also be more likely to contract COVID-19 than their high assets counterparts. Thus, in this way, the stress of civil unrest and COVID-19 may be cumulative and may disproportionately affect persons with low assets, as seen in their higher risk of probable anxiety and depression than persons with high assets.

\section{Limitations}

Some limitations suggest caution in interpreting the current findings. First, our data are cross-sectional, limiting causal inference. This is generally a central concern in studies of social stressors and mental health, whereby each of these variables can drive the other. However, in the context of exogenous stressors such as a pandemic and social unrest it seems less likely that poor mental health is driving exposure to these stressors lending credibility to the likelier causal associations inferred here. Second, we used diagnostic screeners rather than clinical diagnoses to assess probable anxiety and depression in the current study. We did use, however, the GAD-7 and PHQ-9, well validated and widely used with established norms across different Chinese populations in Greater China [2]. Third, the generalizability of the current findings to other regions should be considered with caution. The incidence and mortality rates of COVID-19 were relatively mild in Hong Kong during the study period (Feb 25-May 1, 2020) compared to other major cities/regions such as New York, London, and Singapore. Nevertheless, prior studies have reported high prevalences of probable anxiety and depression amid COVID-19 pandemic in population-based studies in Hong Kong [50, 51], while COVID-19 related stressors/events were also found to be positively associated with mental illnesses across regions under the differing impact of COVID-19 [52, 53]. More research is needed to examine whether the mental health impact of civil unrest is stronger than that of the pandemic in regions that are more severely affected by social unrest. Fourth, more specific COVID-19 stressors were not assessed, although our findings documented some of the first preliminary evidence on the associations of unrestCOVID-19 stressors with population mental health across persons with low and high assets.

\section{Conclusions}

This study provides initial evidence that can inform future research on population mental health during the pandemic particularly in regions affected by regular and widespread unrest or conflicts. Massive civil unrest against police violence and racism has been going on across different states in the U.S. since the death of George Floyd on May 25th, 2020. COVID-19 stress coupled with lingering concerns about poverty and racism in the US could therefore both contribute to initiating civil unrest and-as suggested in the current study-unrest stress and COVID-19 stress can together lead to a higher risk of significant psychiatric symptoms in the population [27]. Considered the tremendous increase in COVID-19 infection rates across the globe, future studies could examine the impact of unrest and COVID-19 stressors on mental health, especially among COVID-19 positive cases.

Supplementary Information The online version contains supplementary material available at https://doi.org/10.1007/s00127-021-02037-5.

\section{Acknowledgements None.}

Author contributions W-KH: conceptualization, funding acquisition, methodology, formal analysis, data curation, and writing - original draft. TM-CL: funding acquisition and writing-review and editing. LL: formal analysis, data curation, and writing - review and editing. TWL: data curation and writing-review and editing. HL: writingreview and editing. CKE: writing - review and editing. SG: conceptualization, methodology, and writing—original draft.

Funding This research was supported by Public Policy Research Fund from Policy Innovation and Coordination Office, Hong Kong SAR Government [SR2020.A5.019 to WKH], and Collaborative Research 
Fund, Research Grants Council, University Grants Committee, Hong Kong SAR, China [C7069-19GF to TMCL and WKH].

Availability of data and material All will be made freely available upon request to the corresponding author.

Code availability All will be made freely available upon request to the corresponding author.

\section{Compliance with ethical standards}

Conflict of interest The authors declare no conflict of interest.

Ethical standards This study has been approved by the Human Research Ethics Committee of The Education University of Hong Kong (2019-2020-0224). All respondents gave active informed consent prior to inclusion in the study.

\section{References}

1. Hong Kong Public Opinion Research Institute, Project Citizen Foundation (2020) Anti-Extradition bill movement - public sentiment report. Hong Kong Public Opinion Research Institute, Project Citizen Foundation. https://static1.squarespace.com/ static/5cfd1ba6a7117c000170d7aa/t/5edf19e20706ce30d2a2 d248/1591679491056/\%5BENG\%5DPCFxPORI_PSR_Revis edVersion.pdf. (Accessed Jun 1 2020)

2. Hou WK, Hall BJ, Canetti D, Lau KM, Ng SM, Hobfoll SE (2015) Threat to democracy: physical and mental health impact of democracy movement in Hong Kong. J Affect Disord 186:74-82. https://doi.org/10.1016/j.jad.2015.07.005

3. Ni MY, Yao XI, Leung KSM et al (2020) Depression and posttraumatic stress during major social unrest in Hong Kong: a 10-year prospective cohort study. Lancet 395(10220):273-284. https://doi.org/10.1016/S0140-6736(19)33160-5

4. Hou WK, Hall BJ, Liang L, Li TW, Liu H, Galea S (2021) Probable depression and suicidal ideation in Hong Kong amid massive civil unrest. Ann Epidemiol 54:45-51. https://doi.org/10.1016/j. annepidem.2020.09.006

5. Hou WK, Bonanno GA (2018) Emotions in everyday life during social movements: Prospective predictions of mental health. J Couns Psychol 65(1):120-131. https://doi.org/10.1037/cou00 00236

6. Holmes EA, O'Connor RC, Perry VH et al (2020) Multidisciplinary research priorities for the COVID-19 pandemic: a call for action for mental health science. Lancet Psychiatry 7(6):547-560. https://doi.org/10.1016/S2215-0366(20)30168-1

7. Pearlin LI, Aneshensel CS, LeBlanc AJ (1997) The forms and mechanisms of stress proliferation: the case of AIDS caregivers. J Health Soc Behav 38(3):223-236. https://doi.org/10.2307/29553 68

8. Stevens NR, Gerhart J, Goldsmith RE, Heath NM, Chesney SA, Hobfoll SE (2013) Emotion regulation difficulties, low social support, and interpersonal violence mediate the link between childhood abuse and posttraumatic stress symptoms. Behav Ther 44(1):152-161. https://doi.org/10.1016/j.beth.2012.09.003

9. Heinze JE, Cook SH, Wood EP, Dumadag AC, Zimmerman MA (2018) Friendship attachment style moderates the effect of adolescent exposure to violence on emerging adult depression and anxiety trajectories. J Youth Adolesc 47(1):177-193. https://doi. org/10.1007/s10964-017-0729-x
10. Ettman CK, Cohen GH, Galea S (2020) Is wealth associated with depressive symptoms in the United States? Ann Epidemiol 43:25-31. https://doi.org/10.1016/j.annepidem.2020.02.001

11. Chung RY, Chung GK, Gordon D et al (2020) Housing affordability effects on physical and mental health: household survey in a population with the world's greatest housing affordability stress. J Epidemiol Community Health 74(2):164-172. https:// doi.org/10.1136/jech-2019-212286

12. Leung GM, Ho LM, Chan SK et al (2005) Longitudinal assessment of community psychobehavioral responses during and after the 2003 outbreak of severe acute respiratory syndrome in Hong Kong. Clin Infect Dis 40(12):1713-1720. https://doi. org/10.1086/429923

13. Galea S, Tracy M (2007) Participation rates in epidemiologic studies. Ann Epidemiol 17(9):643-653. https://doi.org/10.1016/j. annepidem.2007.03.013

14. Spitzer RL, Kroenke K, Williams JB, Löwe B (2006) A brief measure for assessing generalized anxiety disorder: the GAD-7. Arch Intern Med 166(10):1092-1097. https://doi.org/10.1001/ archinte.166.10.1092

15. Plummer F, Manea L, Trepel D, McMillan D (2016) Screening for anxiety disorders with the GAD-7 and GAD-2: a systematic review and diagnostic metaanalysis. Gen Hosp Psychiatry 39:24 31. https://doi.org/10.1016/j.genhosppsych.2015.11.005

16. Yeung A, Fung F, Yu SC et al (2008) Validation of the patient health questionnaire-9 for depression screening among Chinese Americans. Compr Psychiatry 49(2):211-217. https://doi. org/10.1016/j.comppsych.2006.06.002

17. Levis B, Benedetti A, Riehm KE, Thombs BD, DEPRESsion Screening Data (DEPRESSED) Collaboration (2019) Accuracy of patient health questionnaire-9 (PHQ-9) for screening to detect major depression: individual participant data meta-analysis. BMJ 365:1-11. https://doi.org/10.1136/bmj.11476

18. Szabo A, Allen J, Alpass F, Stephens C (2018) Longitudinal trajectories of quality of life and depression by housing tenure status. J Gerontol B Psychol Sci Soc Sci 73(8):e165-e174. https://doi. org/10.1093/geronb/gbx028

19. Credit Suisse (2019) Global wealth report 2019. Credit Suisse. https://www.credit-suisse.com/about-us/en/reports-research/globa 1-wealth-report.html. (Accessed Jun 12020 )

20. Meraya AM, Dwibedi N, Innes K, Mitra S, Tan X, Sambamoorthi U (2018) Heterogeneous relationships between labor income and health by race/ethnicity. Health Serv Res 53:2910-2931. https:// doi.org/10.1111/1475-6773.12802

21. Pieh C, Budimir S, Probst T (2020) The effect of age, gender, income, work, and physical activity on mental health during coronavirus disease (COVID-19) lockdown in Austria. J Psychosom Res 136:110186. https://doi.org/10.1016/j.jpsychores.2020.11018 6

22. Ettman CK, Abdalla SM, Cohen GH, Sampson L, Vivier PM, Galea S (2020) Low assets and financial stressors associated with higher depression during COVID-19 in a nationally representative sample of US adults. J Epidemiol Community Health. Advance online publication. https://doi.org/10.1136/jech-2020-215213

23. Census and Statistics Department (2020) Hong Kong in Figures. Census and Statistics Department. https://www.statistics.gov.hk/ pub/B10100062020AN20B0100.pdf. (Accessed Jun 12020 )

24. Galea S, Merchant RM, Lurie N (2020) The mental health consequences of COVID-19 and physical distancing: the need for prevention and early intervention. JAMA Intern Med 180(6):817818. https://doi.org/10.1001/jamainternmed.2020.1562

25. Hou WK, Lai FTT, Ben-Ezra M, Goodwin R (2020) Regularizing daily routines for mental health during and after the COVID-19. J Glob Health 10(2):020315. https://doi.org/10.7189/jogh.10.02031 5 
26. Lai FTT, Hall BJ, Liang L, Galea S, Hou WK (2020) Socioeconomic determinants of depression amid the anti-extradition bill protests in Hong Kong: the mediating role of daily routine disruptions. J Epidemiol Community Health 74(12):988-994. https:// doi.org/10.1136/jech-2019-213693

27. Galea S, Abdalla SM (2020) COVID-19 pandemic, unemployment, and civil unrest: underlying deep racial and socioeconomic divides. JAMA 324(3):227-228. https://doi.org/10.1001/ jama.2020.11132

28. Shultz JM, Baingana F, Neria Y (2015) The 2014 Ebola outbreak and mental health: current status and recommended response. JAMA 313(6):567-568. https://doi.org/10.1001/jama.2014.17934

29. Jeong H, Yim HW, Song Y et al (2016) Mental health status of people isolated due to Middle East respiratory syndrome. Epidemiol Health 38:e2016048. https://doi.org/10.4178/epih.e2016048

30. Park HY, Park WB, Lee SH et al (2020) Posttraumatic stress disorder and depression of survivors 12 months after the outbreak of Middle East respiratory syndrome in South Korea. BMC Pub health 20:605. https://doi.org/10.1186/s12889-020-08726-1

31. Mak IW, Chu CM, Pan PC, Yiu MG, Chan VL (2009) Longterm psychiatric morbidities among SARS survivors. Gen Hosp Psychiatry 31(4):318-326. https://doi.org/10.1016/j.genhosppsy ch.2009.03.001

32. McLaughlin KA, Conron KJ, Koenen KC, Gilman SE (2010) Childhood adversity, adult stressful life events, and risk of past-year psychiatric disorder: a test of the stress sensitization hypothesis in a population-based sample of adults. Psychol Med 40(10):1647-1658. https://doi.org/10.1017/S0033291709992121

33. Benson PR, Karlof KL (2009) Anger, stress proliferation, and depressed mood among parents of children with ASD: a longitudinal replication. J Autism Dev Disord 39(2):350-362. https:// doi.org/10.1007/s10803-008-0632-0

34. Census and Statistics Department (2016) Table E305: Gini coefficient by household size, 2006, 2011 and 2016. Census and Statistics Department. https://www.censtatd.gov.hk/hkstat/sub/sp459 .jsp?productCode $=$ D5321605 (Accessed Jan 12020$)$

35. Kivimäki M, Batty G, Pentti J et al (2020) Association between socioeconomic status and the development of mental and physical health conditions in adulthood: a multi-cohort study. Lancet Public Health 5(3):e140-e149. https://doi.org/10.1016/s2468 -2667(19)30248-8

36. Baker EH (2014) Socioeconomic Status, Definition. In: Cockerham WC, Dingwall R, Quah SR (eds) The Wiley Blackwell Encyclopedia of Health, Illness, Behavior, and Society. WileyBlackwell, NJ, pp 2210-2214

37. Lorant V, Deliège $\mathrm{D}$, Eaton $\mathrm{W}$, Robert $\mathrm{A}$, Philippot $\mathrm{P}$, Ansseau M (2003) Socioeconomic inequalities in depression: a meta-analysis. Am J Epidemiol 157(2):98-112. https://doi.org/10.1093/aje/ kwf182

38. Peverill M, Dirks M, Narvaja T, Herts K, Comer J, McLaughlin K (2021) Socioeconomic status and child psychopathology in the United States: a meta-analysis of population-based studies. Clin Psychol Rev 83:101933. https://doi.org/10.1016/j.cpr.2020.10193 3

39. Adler NE, Boyce T, Chesney MA et al (1994) Socioeconomic status and health: the challenge of the gradient. Am Psychol 49(1):15-24. https://doi.org/10.1037/0003-066X.49.1.15

40. Poirier M, Grépin K, Grignon M (2019) Approaches and alternatives to the wealth index to measure socioeconomic status using survey data: a critical interpretive synthesis. Soc Indic Res 148(1):1-46. https://doi.org/10.1007/s11205-019-02187-9
41. Li C (2020) Hong Kong's economy navigating turbulent times. East Asian Policy 12(01):59-71. https://doi.org/10.1142/S1793 930520000057

42. Nicola M, Alsafi Z, Sohrabi C et al (2020) The socio-economic implications of the coronavirus and COVID-19 pandemic: a review. Int J Surg 78:185-193. https://doi.org/10.1016/j. ijsu.2020.04.018

43. Mercer (2020) Mercer 2020 cost of living ranking. Mercer. https ://www.mercer.com/our-thinking/career/cost-of-living.html?utm_ source $=$ mobilityexchange\&utm_medium $=$ internal\&utm_campa ign=mcol1 (Accessed Jan 1 2020)

44. Chan CK (2011) Hong Kong: workfare in the world's freest economy. Int J Soc Welf 20(1):22-32. https://doi.org/10.111 1/j.1468-2397.2009.00712.x

45. Patel V, Burns JK, Dhingra M, Tarver L, Kohrt BA, Lund C (2018) Income inequality and depression: a systematic review and meta-analysis of the association and a scoping review of mechanisms. World Psychiatry 17(1):76-89. https://doi.org/10.1002/ wps. 20492

46. Elbogen EB, Lanier M, Montgomery AE, Strickland S, Wagner HR, Tsai J (2020) Elbogen et al. Respond to "Stressors and Suicide Attempts in a Time of COVID-19". Am J Epidemiol 189(11):1278-1279. https://doi.org/10.1093/aje/kwaa149

47. Carter KN, Blakely T, Collings S, Gunasekara FI, Richardson $\mathrm{K}$ (2009) What is the association between wealth and mental health? J Epidemiol Community Health 63(3):221-226. https:// doi.org/10.1136/jech.2008.079483

48. Kendall GE, Nguyen H, Ong R (2019) The association between income, wealth, economic security perception, and health: a longitudinal Australian study. Health Sociol Rev 28(1):20-38. https ://doi.org/10.1080/14461242.2018.1530574

49. Singh A, Daniel L, Baker E, Bentley R (2019) Housing disadvantage and poor mental health: a systematic review. Am J Prev Med 57(2):262-272. https://doi.org/10.1016/j.amepre.2019.03.018

50. Choi EPH, Hui BPH, Wan EYF (2020) Depression and anxiety in Hong Kong during COVID-19. Int J Environ Res Public Health 17(10):3740. https://doi.org/10.3390/ijerph17103740

51. Hou WK, Lee TMC, Liang L et al (in press) Psychiatric symptoms and behavioral adjustment during the COVID-19 pandemic: evidence from two population-representative cohorts. Transl Psychiatry

52. Ben-Ezra M, Hou WK, Goodwin R (2021) Investigating the relationship between COVID-19-related and distress and ICD-11 adjustment disorder: two cross-sectional studies. BJPsych Open 7(1):e21. https://doi.org/10.1192/bjo.2020.158

53. Goodwin R, Hou WK, Sun S, Ben-Ezra M (2021) Psychological and behavioural responses to COVID-19: a China-Britain comparison. J Epidemiol Community Health 75(2):189-192. https:// doi.org/10.1136/jech-2020-214453

54. Chung RY, Marmot M, Mak JK et al (2020) Deprivation is associated with anxiety and stress. A population-based longitudinal household survey among Chinese adults in Hong Kong. J Epidemiol Community Health. Advance online publication. https://doi. org/10.1136/jech-2020-214728

55. Hou WK, Tong H, Liang L et al (2021) Probable anxiety and components of psychological resilience amid COVID-19: A population-based study. J Affect Disord 282:594-601. https://doi. org/10.1016/j.jad.2020.12.127 